\title{
Supplementation with a calcium rich marine-derived multi-mineral supplement and short-chain fructo-oligosaccharides on serum cytokines in postmenopausal women: results of a 24 month double blind randomized controlled study
}

\author{
B.E. Cronin, P.J. Allsopp, M.M. Slevin, P.J. Magee, M.B.E. Livingstone, J.J. Strain and \\ E.M. McSorley \\ Northern Ireland Centre for Food and Health, University of Ulster, Coleraine, BT52 1SA
}

Supplements are routinely taken, particularly by postmenopausal women to meet the daily required intake of calcium $(\mathrm{Ca})^{(1)}$. Short-chain fructo-oligosaccharides (scFOS) enhance intestinal Ca absorption ${ }^{(2)}$ with a recent study reporting that scFOS combined with $\mathrm{Ca}$ enhances bone turnover markers ${ }^{(3)}$. However, high $\mathrm{Ca}$ intakes via Ca containing supplements have been implicated as a risk factor for cardiovascular disease (CVD) ${ }^{(4)}$. Inflammation is proposed to be a risk factor for CVD ${ }^{(5)}$.The aim of this study was to investigate the effects of a $\mathrm{Ca}$ rich marine-derived multi-mineral supplement (trade name Aquamin) administered alone or in combination with scFOS (trade name Nutraflora) on circulating inflammatory cytokines in postmenopausal women.

A two year double-blind placebo controlled trial originally designed to examine bone health provided a convenience sample for this study. A total of 300 postmenopausal women (mean Body Mass Index (BMI) $27 \cdot 3$ (SD 4.7) kg/m²) aged 47-75 years were randomly assigned to receive; $800 \mathrm{mg}$ of $\mathrm{Ca}(2.4 \mathrm{~g}$ Aquamin), $800 \mathrm{mg}$ of Ca with $3 \mathrm{~g}$ of scFOS (3.2 g Nutraflora) (CaFOS) or maltodextrin (MD). Using stored serum samples, inflammatory markers IL-6, IL-10, IL-4, and TNF- $\alpha$ were analysed at baseline and 24 months using multi-plex enzyme-linked immune assay (ELISA) plates. Intention to treat ANCOVA (using baseline measures as covariates) was conducted to examine treatment effects between groups and controlling for baseline age, BMI and alcohol use.

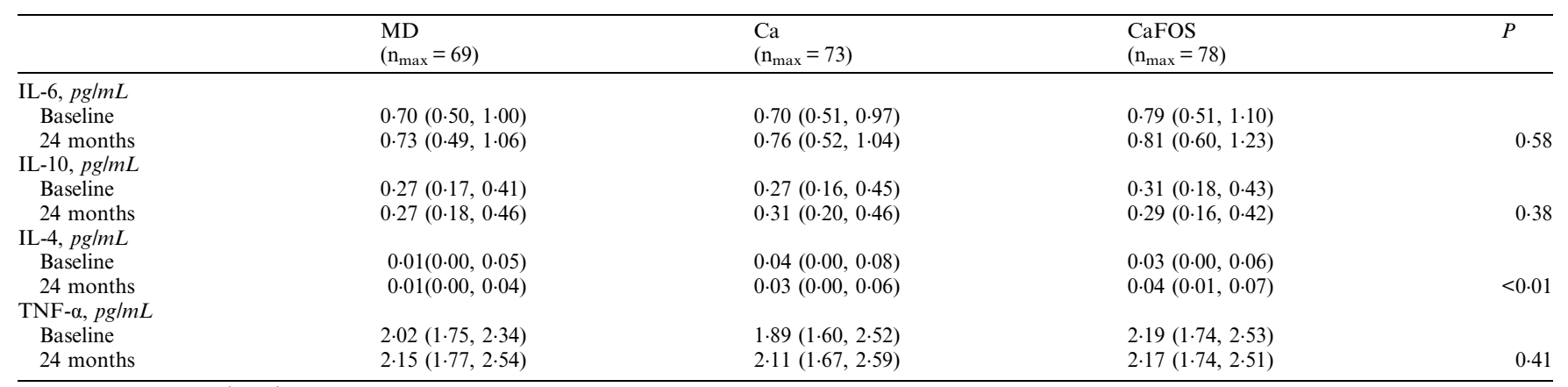

Values are median $\left(25^{\text {th }}, 75^{\text {th }}\right)$. Treatment effects between groups assessed by ANCOVA, significant at $P<0 \cdot 05$.

There was no treatment effect on each of the inflammatory markers assessed except for IL-4 where there was a significant treatment effect in the CaFOS group $(P<0.01)$ following post hoc analysis. Ca combined with scFOS stimulates IL-4 production, an antiinflammatory cytokine which may aid in the suppression of a pro-inflammatory response in postmenopausal women. No pro-inflammatory effect was observed in any of the treatment groups, suggesting that these supplements are not adversely affecting systemic inflammation in this group of postmenopausal women.

This work was funded by Marigot (Cork, Ireland), Ingredion Inc. (Bridgewater, NJ) and a PhD studentship received from the Department for Employment and Learning.

1. Hodgson SF, Watts NB, Bilezekian JP et al. (2003) Endocr Pract 9, 544-64.

2. Tahiri M, Tressol JC, Arnaud J et al. (2003) Am J Clin Nutr 77, 449-57.

3. Slevin MM, Allsopp PJ, Magee PJ et al. (2014) J Nutr 144(3), 297-304.

4. Bolland MJ, Grey A, Avenell A et al. (2011) BMJ 342; d2040.

5. Willerson JT \& Ridker PM (2004) Circulation 109, II-2-II-10. 